Research Publication No. 2007-16

December 2007

\title{
Why Youth Heart Social Network Sites: The Role of Networked Publics in Teenage Social Life
}

Danah Boyd

This paper can be downloaded without charge at:

The Berkman Center for Internet \& Society Research Publication Series: http://cyber.law.harvard.edu/publications

The Social Science Research Network Electronic Paper Collection:

http://papers.ssrn.com/sol3/papers.cfm?abstract_id=1345415 


\title{
Why Youth Social Network Sites: The Role of Networked Publics in Teenage Social Life
}

\author{
danah boyd \\ University of California, Berkeley, School of Information
}

If you're not on MySpace, you don't exist —Skyler, 18, to her mom ${ }^{1}$

I'm in the 7th grade. I'm 13. I'm not a cheerleader. I'm not the president of the student body. Or captain of the debate team. I'm not the prettiest girl in my class. I'm not the most popular girl in my class. I'm just a kid. I'm a little shy. And it's really hard in this school to impress people enough to be your friend if you're not any of those things. But I go on these really great vacations with my parents between Christmas and New Year's every year. And I take pictures of places we go. And I write about those places. And I post this on my Xanga. Because I think if kids in school read what I have to say and how I say it, they'll want to be my friend -Vivien, 13, to Parry Aftab during a "Teen Angels" meeting ${ }^{2}$

During 2005, online social network sites like MySpace and Facebook became common destinations for young people in the United States. Throughout the country, young people were logging in, creating elaborate profiles, publicly articulating their relationships with other participants, and writing extensive comments back and forth. By early 2006, many considered participation on the key social network site, MySpace, essential to being seen as cool at school. While not all teens are members of social network sites, these sites developed significant cultural resonance amongst American teens in a short period of time. Although the luster has since faded and teens are not nearly as infatuated with these sites as they once were, they continue to be an important part of teen social life.

The rapid adoption of social network sites by teenagers in the United States and in many other countries around the world raises some important questions. Why do teenagers flock to these sites? What are they expressing on them? How do these sites fit into their lives? What are they learning from their participation? Are these online activities like face-to-face friendships or are they different, or complementary? The goal of this chapter is to address these questions and explore their implications for youth identities. While particular systems may come and go, how youth engage through social network sites today provides long-lasting insights into identity formation, status negotiation, and peer-to-peer sociality.

This work could not have been done without the support of and conversations with numerous people and groups. In particular, I would like to thank Peter Lyman, Mimi Ito, Marc Davis, and Cori Hayden for their advice and unbelievable amount of support. I would also like to thank everyone on the Digital Youth Project and especially Dan Perkel for sharing amazing insights into teen life. I would also like to thank Irina Shklovski, Fred Stutzman, Nicole Ellison, and Tom Anderson for long nights spent discussing social network sites and youth practices. Finally, I am forever grateful to the Berkeley School of Information and the USC Annenberg Center for Communications for giving me a home in which to think crazy thoughts. 
To address the aforementioned questions, I begin by documenting the key features of social network sites and the business decisions that lead to mass adoption, and then seek to situate social network sites in a broader discussion of what I call "networked publics." I then examine how teens are modeling identity through social network profiles so that they can write themselves and their community into being. Building on this, I investigate how this process of articulated expression supports critical peer-based sociality because, by allowing youth to hang out amongst their friends and classmates, social network sites are providing teens with a space to work out identity and status, make sense of cultural cues, and negotiate public life. I argue that social network sites are a type of networked public with four properties that are not typically present in face-to-face public life: persistence, searchability, replicability, and invisible audiences. These properties fundamentally alter social dynamics, complicating the ways in which people interact. I conclude by reflecting on the social developments that have prompted youth to seek out networked publics, and considering the changing role that publics have in young people's lives.

\section{Methodology and Demographics}

The arguments made in this chapter are based on ethnographic data collected during my twoyear study of U.S.-based youth engagement with MySpace. In employing the term ethnography, I am primarily referencing the practices of "participant observation" and "deep hanging out" $^{3}$ alongside qualitative interviews. I have moved between online and offline spaces, systematically observing, documenting, and talking to young people about their practices and attitudes.

While the subjects of my interviews and direct observations are primarily urban youth (differing in age, sex, race, sexuality, religion, ethnicity, and socioeconomic class), I have also spent countless hours analyzing the profiles, blogs, and commentary of teenagers throughout the United States. Although I have interviewed older people, the vast majority of people that I have interviewed and observed are of high school age, living with a parent or guardian. There is no good term to reference this group. Not all are actually students (and that role signals identity material that is not accurate). Vague terms like "youth," "young people," and "children" imply a much broader age range. For these reasons, and in reference to the history of the term "teenager" in relation to compulsory high school education, ${ }^{4}$ I have consciously decided to label the relevant population "teenagers" even though the majority of individuals that I have spoken with are between the age group of fourteen to eighteen. While strictly speaking, there are teenagers who are not in high school, the vast majority of those fourteen to eighteen are high school students; I will focus primarily on that group.

In examining the practices of teenagers on social network sites, I focus primarily on MySpace. This will be my primary case study, although my discussion of these sites is applicable more broadly; I will reference other sites as appropriate. I should note that prior to studying teen practices on MySpace, I did a two-year ethnographic study of Friendster, another social network site. While it is unlikely that MySpace will forever be the main destination site for teenagers, I use this site because its mass popularity offers critical insight into participation patterns that do and will exist on other sites.

Although news media give the impression that all online teens in the United States are on MySpace, this is not the case. For this reason, I want to take a moment to discuss who is not participating. In 2004, PEW found that 87 percent of teenagers aged twelve to seventeen have some level of Internet access. ${ }^{5}$ In a study conducted in late 2006, they found that 
55 percent of online teens aged twelve to seventeen have created profiles on social network sites with 64 percent of teens aged fifteen to seventeen. ${ }^{6}$ While these numbers are most likely low, ${ }^{7}$ it is very clear that not all high school students participate in online communities that require public content creation like social network sites.

Qualitatively, I have found that there are two types of nonparticipants: disenfranchised teens and conscientious objectors. The former consists of those without Internet access, those whose parents succeed in banning them from participation, and online teens who primarily access the Internet through school and other public venues where social network sites are banned. ${ }^{8}$ Conscientious objectors include politically minded teens who wish to protest against Murdoch's News Corp. (the corporate owner of MySpace), obedient teens who have respected or agree with their parents' moral or safety concerns, marginalized teens who feel that social network sites are for the cool kids, and other teens who feel as though they are too cool for these sites. The latter two explanations can be boiled down to one explanation that I heard frequently: "because it's stupid." While the various conscientious objectors may deny participating, I have found that many of them actually do have profiles to which they log in occasionally. I have also found numerous cases where the friends of nonparticipants create profiles for them. ${ }^{9}$ Furthermore, amongst those conscientious objectors who are genuinely nonparticipants, I have yet to find one who does not have something to say about the sites, albeit typically something negative. In essence, MySpace is the civil society of teenage culture: whether one is for it or against it, everyone knows the site and has an opinion about it.

Interestingly, I have found that race and social class play a little role in terms of access beyond the aforementioned disenfranchised population. Poor urban black teens appear to be just as likely to join the site as white teens from wealthier backgrounds, although what they do on there has much to do with their level of Internet access. Those who only access their accounts in schools use it primarily as an asynchronous communication tool, while those with continuous nighttime access at home spend more time surfing the network, modifying their profile, collecting friends, and talking to strangers. When it comes to social network sites, there appears to be a far greater participatory divide than an access divide.

Gender also appears to influence participation on social network sites. Younger boys are more likely to participate than younger girls (46 percent vs. 44 percent) but older girls are far more likely to participate than older boys (70 percent vs. 57 percent). Older boys are twice as likely to use the sites to flirt and slightly more likely to use the sites to meet new people than girls of their age. Older girls are far more likely to use these sites to communicate with friends they see in person than younger people or boys of their age. ${ }^{10}$ While gender differences do exist and should not be ignored, most of what I discuss in this article concerns practices that are common to both boys and girls.

Fundamentally, this chapter is a case study based on ethnographic data. My primary goal is simply to unveil some of the common ways in which teenagers now experience social life online.

\section{The Making of Social Network Sites}

Although a handful of sites predated it, Friendster popularized the features that define contemporary social network sites-profiles, public testimonials or comments, and publicly articulated, traversable lists of friends. Launched in 2002 as a newfangled dating site, Friendster quickly became popular amongst mid-twenty/thirty-something urban dwellers living in the United States. Although some used the site for its intended purpose of meeting potential 
partners, others engaged in a wide array of activities, ranging from tracking down high school mates to creating fictional profiles for entertainment purposes. ${ }^{11}$ By the summer of 2003, some San Francisco-based bands realized that they could leverage the site to connect to their fans and promote their gigs. ${ }^{12}$ Word spread in the relevant music scenes, although Friendster forbade this practice and began deleting bands' profiles (along with any profile deemed "fake"). When MySpace launched in the fall of 2003, they welcomed bands online, quickly attracting the attention of indie rock musicians from the Silverlake neighborhood of Los Angeles.

Music is cultural glue among youth. As the bands began advertising their presence on MySpace, mid-twenty/thirty-something club goers jumped on board in the hopes of gaining access to VIP passes or acquiring valuable (sub)cultural capital. ${ }^{13}$ While fans typically have to be twenty-one plus in the United States to get into the venues where bands play (because of alcohol laws), younger audiences are avid consumers of music and the culture that surrounds it. When young music aficionados learned that their favorite bands had profiles on MySpace, they began checking out the site. Music junkies loved the fact that they could listen to and download music for free while celebrity watchers enjoyed writing to musicians who were happy to respond. A symbiotic relationship between bands and fans quickly emerged on the system as bands wanted to gather fans and fans wanted to be connected to their favorite bands. Given the degree to which youth are active participants in music subcultures, it is not surprising that MySpace attracted young fans.

While the first wave of young participants learned of the site through their interest in music and musicians, they also invited their less musically engaged peers to join the site. Many began participating because of the available social voyeurism and the opportunity to craft a personal representation in an increasingly popular online community. Just like their older counterparts, teenagers loved the ability to visualize their social world through the networked collection of profiles. At the same time, younger participants adopted different participation strategies from those of earlier, older participants. While many adults find value in socializing with strangers, teenagers are more focused on socializing with people they knew personally and celebrities that they adore.

By mid-2005, MySpace was a popular destination for high school students throughout the United States but teenagers from other countries were on a variety of other social network sites. Friendster had lost its grip on twenty/thirty-something urbanites but it had become popular amongst teenagers in Singapore, Philippines, Indonesia, and Malaysia. Social network sites like Orkut and Hi5, which were initially popular among adults in Brazil and India, began attracting the attention of younger audiences in those countries. Facebook, a United States site for college students, opened its door to high school students in September 2005. In other regions, new social network sites were launched explicitly to attract the attention of teens. Sites like Tagworld, Bebo, Piczo, Faceparty, and Mixi all launched with youth in mind and took off in places like the United Kingdom, New Zealand, Australia, and Japan. Preexisting community sites like Black Planet, Asian Avenue, and MiGente implemented social network site features, although this did not help them regain the teens that they had lost to MySpace. In China, an instant messaging service called QQ added social network site features, as did the popular Korean community site Cyworld; both are popular across all age groups in China and South Korea.

Most of the social network sites were brewed by venture-backed startups, but there are a few exceptions to this. Cyworld is a property of SK Telecom, the largest mobile phone operator in South Korea. Orkut began as a side project by a Google employee but, shortly 
before launch, Google decided to attach its name to the site so that it launched as a Google project. Microsoft, Yahoo!, AOL, and Wal-Mart have all created social network sites, but these have not been particularly successful. In 2005, Fox Interactive Media (a division of Murdoch's News Corporation) purchased MySpace for US \$580 million. Unfortunately, not much is currently known about the long-term effects of corporate participation in social network sites. While there has been tremendous speculation about what Fox's ownership of MySpace will mean, there have been few changes made since the site was acquired. Of course, broader concerns about the impact of consumer culture on young people's agency ${ }^{14}$ in online participation are completely applicable to social network sites.

While there are dozens of social network sites, participation tends to follow cultural and linguistic lines. Few sites successfully support groups from different nation-states; although Orkut is popular in both India and Brazil, Cyworld has large audiences in China and South Korea, and MySpace is trying to grow globally. Cyworld has completely separate domains that segregate the Koreans from the Chinese. On Orkut, the Indians and Brazilians share the site but barely interact with one another. Furthermore, the Indian participants have segmented themselves within the system along caste lines. ${ }^{15}$ Even on MySpace where there is a strong American culture, there is an intense division along race and age lines. While cultural forces clearly segment participation, there are many structural similarities across the sites. Fundamentally, social network sites are a category of community sites that have profiles, friends, and comments.

\section{Profiles, Friends, and Comments}

Social network sites are based around profiles, a form of individual (or, less frequently, group) home page, which offers a description of each member. In addition to text, images, and video created by the member, the social network site profile also contains comments from other members and a public list of the people that one identifies as Friends within the network. ${ }^{16}$ Because the popularized style of these sites emerged out of dating services, the profile often contains material typical of those sites: demographic details (age, sex, location, etc.), tastes (interests, favorite bands, etc.), a photograph, and an open-ended description of who the person would like to meet. Profiles are constructed by filling out forms on the site. While the forms were designed to control the layout of the content, MySpace accidentally left open a technological loophole and their forms accepted (and then rendered) HTML and CSS code. Capitalizing on this loophole, participants can modify the look and feel of their profiles. By copying and pasting code from other websites, teens change their backgrounds, add video and images, change the color of their text, and otherwise turn their profiles into an explosion of animated chaos that resembles a stereotypical teenager's bedroom. The default profile is publicly accessible to anyone, but most social network sites have privacy features that allow participants to restrict who can see what. For example, MySpace allows participants to make their profiles Friends-only (and sets this as the default for those who indicate they are fourteen or fifteen years old) while Facebook gives profile-access only to people from the same school by default.

After creating a profile, participants are asked to invite their friends to the site by supplying their email addresses. Alternatively, they can look at others' profiles and add those people to their list of Friends. ${ }^{17}$ Most social network sites require approval for two people to be linked as Friends. When someone indicates another as a Friend, the recipient receives a message asking for confirmation. If Friendship is confirmed, the two become Friends in the system and their relationship is included in the public display of connections on all profiles. ${ }^{18}$ These 


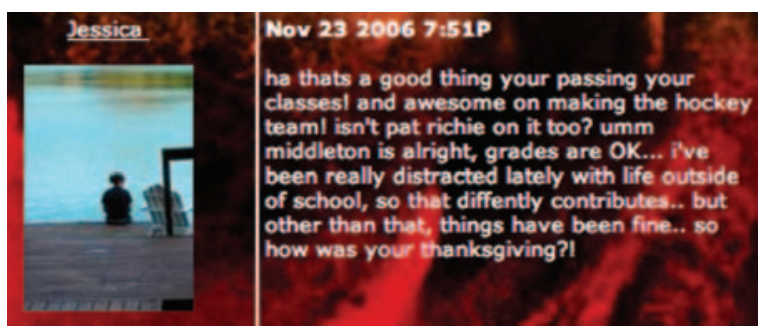

Figure 1

Conversation as MySpace comment.

displays typically involve photos and nicknames that link to their profile. By clicking on these links, visitors can traverse the network by surfing from Friend to Friend to Friend.

In addition to the content that members provide to create their own profiles, social network sites typically have a section dedicated to comments by Friends. (On Friendster, this section is called Testimonials; on Facebook, it is called The Wall.) Because Friendster implemented this feature to encourage people to write testimonials about their friends for strangers to read, early adopters used this feature to write single messages about the person represented in the profile. Over time, reciprocity motivated people to write creative testimonials back and forth, creating a form of conversation ${ }^{19}$; this was particularly popular amongst people using Friendster for playful activities (see Figure 1). For example, a profile representing table salt wrote long love odes about pepper on the profile representing pepper; pepper reciprocated and this went back and forth for weeks.

As teenagers began joining Friendster, they also used this section to write to the profile owner, even though the testimonials were public. When MySpace implemented the same feature and called it Comments instead of Testimonials, writing to the person became status quo, particularly amongst younger participants (see Figure 1). The following comments highlight the difference:

Mark is a man among boys, a razor sharp mind towering over the general sludge. (Testimonial on Friendster Profile of Mark, 27)

Are we still gonna go paintballing? (Comment on MySpace Profile of Corey, 14)

In essence, Corey's friend is writing a purportedly private message to him in a public space for others to view. Corey will reply to the comment in kind, writing the answer on his friend's profile. By doing this, teens are taking social interactions between friends into the public sphere for others to witness.

Although many sites include other common features, ${ }^{20}$ the practices that take place through the use of the most prevalent three-profiles, friends, and comments—differentiate social network sites from other types of computer-mediated communication. Furthermore, what makes these three practices significant for consideration is that they take place in public: Friends are publicly articulated, profiles are publicly viewed, and comments are publicly visible.

\section{Networked Publics}

Defining the term public is difficult at best. ${ }^{21}$ As an adjective, it is commonly used in opposition to private. When referring to locations, public is used to signal places that are accessible 
to anyone (or at least anyone belonging to a privileged category like adults). In reference to actions or texts, public often implies that the audience is unknown and that strangers may bear witness.

As a noun, public refers to a collection of people who may not all know each other but share "a common understanding of the world, a shared identity, a claim to inclusiveness, a consensus regarding the collective interest." ${ }^{22}$ In some senses, public is quite similar to audience as both refer to a group bounded by a shared text, whether that is a worldview or a performance. ${ }^{23}$ These words often collide conceptually because speaking to the public implies that the public is acting as an audience.

When talking about the public, one must ask if there is only one public. When United States' President Bush addresses the public, he is not conceptualizing the same public as Zimbabwe's President Mugabe would. Likewise, it is not the same audience that hears both presidents. If, instead, we talk about a public, it is possible to recognize that there are different collections of people depending on the particular situation. ${ }^{24}$ Talking about a public also implies that there must be multiple publics separated by social contexts. What then constitutes the boundaries of a given public?

In this article, I move between these many different meanings of public. Social network sites allow publics to gather. At the same time, by serving as a space where speech takes place, they are also publics themselves. The sites themselves also distinguish between public and private, where public means that a profile is visible to anyone and private means that it is Friends-only.

The types of publics that gather on social network sites and the types of publics that such sites support are deeply affected by the mediated nature of interaction. For these reasons it is important to distinguish these sites as publics, not simply public, and networked publics, not simply publics. While this latter term has been used to reference "a linked set of social, cultural, and technological developments that have accompanied the growing engagement with digitally networked media, ${ }^{25}$ I am primarily talking about the spaces and audiences that are bound together through technological networks (i.e. the Internet, mobile networks, etc.). Networked publics are one type of mediated public; the network mediates the interactions between members of the public. Media of all stripes have enabled the development of mediated publics.

The reason for differentiating networked publics from mediated and unmediated publics has to do with fundamental architectural differences that affect social interaction. In unmediated environments, the boundaries and audiences of a given public are structurally defined. Access to visual and auditory information is limited by physics; walls and other obstacles further restrain visibility. Thus when I say that I embarrassed myself in public by tripping on the curb, the public that I am referencing includes all of the strangers who visually witnessed my stumble. The audience is restricted to those present in a limited geographical radius at a given moment in time. The public that I conceptualize might also include all of those who might hear of my accident through word of mouth, although the likelihood of others sharing the event is dependent on my status in the public and the juiciness of the story. While I might think that the whole world must know, this is not likely to be true. More importantly, in an unmediated world, it is not possible for the whole world actually to witness this incident; in the worst-case scenario, they might all hear of my mishap through word of mouth.

Mediating technologies like television, radio, and newsprint change everything. My fall could have been recorded and televised on the nightly news. This changes the scale of 
the public. Rather than considering all of the people who did witness me visually, I must also consider all of the people who might witness a reproduction of my fall. The potential audience is affected by the properties of the mediating technologies, namely persistence, replicability, and invisible audiences. Networked publics add an additional featuresearchability-while magnifying all of the other properties. While broadcast media take advantage of persistence, it is not as if anyone could go to the television and watch my fall whenever they wish, but if my fall is uploaded to YouTube or MySpace Video, this is possible.

These four properties thus fundamentally separate unmediated publics from networked publics:

1 Persistence: Unlike the ephemeral quality of speech in unmediated publics, networked communications are recorded for posterity. This enables asynchronous communication, but it also extends the period of existence of any speech act.

2 Searchability: Because expressions are recorded and identity is established through text, search and discovery tools help people find like minds. While people cannot currently acquire the geographical coordinates of any person in unmediated spaces, finding one's digital body online is just a matter of keystrokes.

3 Replicability: Hearsay can be deflected as misinterpretation, but networked public expressions can be copied from one place to another verbatim such that there is no way to distinguish the "original" from the "copy." 26

4 Invisible audiences: While we can visually detect most people who can overhear our speech in unmediated spaces, it is virtually impossible to ascertain all those who might run across our expressions in networked publics. This is further complicated by the other three properties, since our expression may be heard at a different time and place from when and where we originally spoke.

In short, a mediated public (and especially a networked public) could consist of all people across all space and all time. Of course, in reality, it probably will not, even when a person desperately wishes to have such attention. Still, the bounding forces of networked publics are less constrained by geography and temporal collocation than unmediated publics. Because people are not accustomed to socializing when they do not know the audience or the context, interactions in networked publics are often peculiar to newcomers who get frustrated when what they intended is not what is interpreted.

These properties affect both the potential audience and the context in which the expression is received. We will address this further in the next section as we consider young people's engagement with social network sites more specifically.

\section{Participation}

When I ask teenagers why they joined MySpace, the answer is simple: "Cuz that's where my friends are." Their explanation of what they do on the site is much more vague: "I don't know... I just hang out." Beneath these vague explanations is a clear message: the popularity of MySpace is deeply rooted in how the site supports sociality amongst preexisting friend groups. Teens join MySpace to maintain connections with their friends. ${ }^{27}$

While socializing drives certain kinds of engagement with the site, teens with Internet access at home offer another plausible explanation for the long hours they spend there: "because I was bored." 


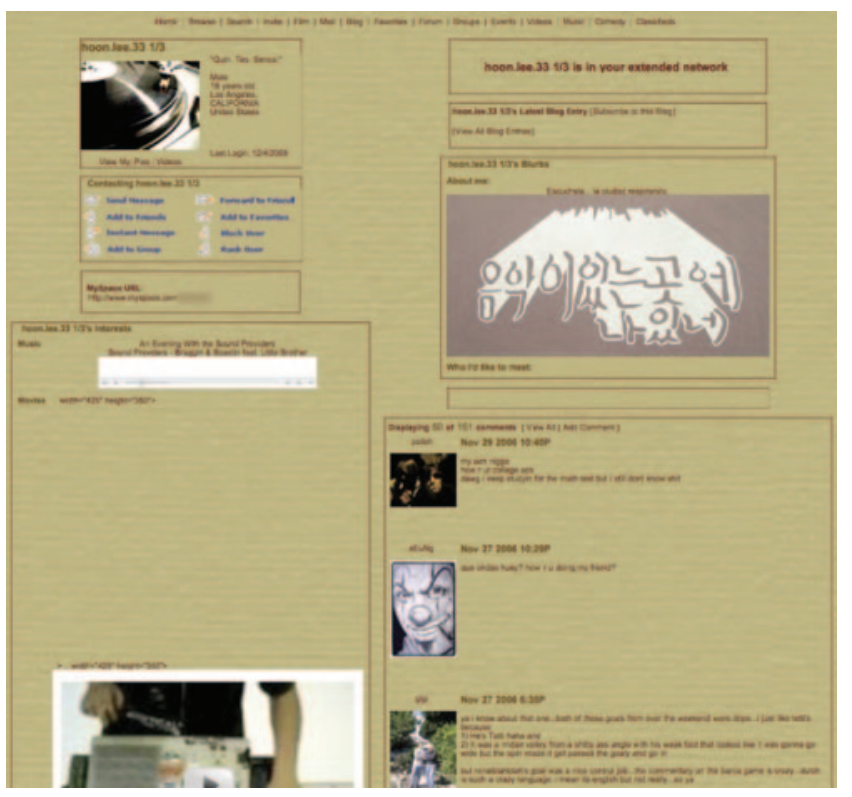

Figure 2

Example profile featuring modified background and multimedia.

Just because I'm on the computer at 2:30 am, doesn't mean I'm up to no good. Like last night (my mom) comes in and yells at me to go to bed. When I don't, she is all 'well what are you doing, show me what you're doing.' Of course I was lurking MySpace profiles, cause there is nothing better to do, but that's annoying to explain, she wouldn't understand. -Pam, 17

Teens often turn to sites like MySpace for entertainment; social voyeurism passes time while providing insight into society at large.

In the next three sections, I examine three different aspects of teenage practices on MySpace. First, I discuss the profile construction process in light of how teens are working through impression management and identity issues. I then turn to consider teens' conceptions of public, private, and context. Finally, I discuss changing historical constructions of youth publics, in order to shed light on why so much critical social development is taking place online in sites like MySpace.

\section{Initiation: Profile Creation}

Teenagers typically learn about MySpace through their friends-they join because a friend invites them to join. After creating an account, they begin setting up their profile by filling in forms on the site (see Figure 2 for an example profile). This generates a generic profile with content like "favorite books" and "about me." Before writing anything of depth, teens tend to look at others' profiles, starting with the friend who invited them. In viewing that profile, they are offered links to their friends' MySpace Friends, and so they can spend countless hours surfing the network, jumping from Friend to Friend. By looking at others' profiles, teens get a sense of what types of presentations are socially appropriate; others' profiles provide critical cues about what to present on their own profile. While profiles are constructed through a series of generic forms, there is plenty of room for them to manipulate the profiles to express 
themselves. At a basic level, the choice of photos and the personalized answers to generic questions allow individuals to signal meaningful cues about themselves. While the ability to identify oneself through such textual and visual means is valuable, MySpace profiles also afford another level of personalization (see Figure 2).

Experimenting with the generic forms, a few early adopters discovered that MySpace had failed to close a security hole. While most other sites blocked HTML, CSS, and Javascript in their forms, MySpace did not. Early adopters began exploiting this hole to personalize their pages by adding code to the form fields that changed the background and added multimedia to their pages. There is no simple way to make these modifications ${ }^{28}$; individuals must figure out what CSS or HTML goes in what form. While the site itself does not offer support, numerous other websites (most initially created by teenagers) emerged to provide code and instructions for modifying every aspect of a MySpace page. Individuals choose a desirable layout and then they are instructed to copy and paste the code into the appropriate forms. This code inevitably includes links back to the helper page. ${ }^{29}$ A copy/paste culture emerged, as teens began trafficking in knowledge of how to pimp out ${ }^{30}$ their profiles. Although most teens' profiles are altered, it is important not to assume technological literacy ${ }^{31}$ — few teens hand-code their pages; most use a helper site or beg friends to do it for them.

Building an intricate profile is an initiation rite. In the early days of their infatuation, teens spend innumerable hours tracking down codes, trading tips, and setting up a slick profile. Through this process, they are socialized into MySpace-they learn both technological and social codes. While technological information gives them the wherewithal to craft a profile, the interpretation and evaluation of this performance is dictated by social protocols. MySpace profiles become yet another mechanism by which teens can signal information about their identities and tastes.

\section{Identity Performance}

In everyday interactions, the body serves as a critical site of identity performance. In conveying who we are to other people, we use our bodies to project information about ourselves. ${ }^{32}$ This is done through movement, clothes, speech, and facial expressions. What we put forward is our best effort at what we want to say about who we are. Yet while we intend to convey one impression, our performance is not always interpreted as we might expect. Through learning to make sense of others' responses to our behavior, we can assess how well we have conveyed what we intended. We can then alter our performance accordingly. This process of performance, interpretation, and adjustment is what Erving Goffman calls impression management, ${ }^{33}$ and is briefly discussed in the introduction to this volume. Impression management is a part of a larger process where people seek to define a situation ${ }^{34}$ through their behavior. People seek to define social situations by using contextual cues from the environment around them. Social norms emerge out of situational definitions, as people learn to read cues from the environment and the people present to understand what is appropriate behavior.

Learning how to manage impressions is a critical social skill that is honed through experience. Over time, we learn how to make meaning out of a situation, others' reactions, and what we are projecting of ourselves. As children, we learn that actions on our part prompt reactions by adults; as we grow older, we learn to interpret these reactions and adjust our behavior. Diverse social environments help people develop these skills because they force individuals to reevaluate the signals they take for granted. 
The process of learning to read social cues and react accordingly is core to being socialized into a society. While the process itself begins at home for young children, it is critical for young people to engage in broader social settings to develop these skills. Of course, how children are taught about situations and impression management varies greatly by culture, ${ }^{35}$ but these processes are regularly seen as part of coming of age. While no one is ever a true master of impression management, the teenage years are ripe with opportunities to develop these skills.

In mediated environments, bodies are not immediately visible and the skills people need to interpret situations and manage impressions are different. As Jenny Sundén argues, people must learn to write themselves into being. ${ }^{36}$ Doing so makes visible how much we take the body for granted. While text, images, audio, and video all provide valuable means for developing a virtual presence, the act of articulation differs from how we convey meaningful information through our bodies. This process also makes explicit the self-reflexivity that Giddens argues is necessary for identity formation, but the choices individuals make in crafting a digital body highlight the self-monitoring that Foucault describes. ${ }^{37}$

In some sense, people have more control online-they are able to carefully choose what information to put forward, thereby eliminating visceral reactions that might have seeped out in everyday communication. At the same time, these digital bodies are fundamentally coarser, making it far easier to misinterpret what someone is expressing. Furthermore, as Amy Bruckman shows, key information about a person's body is often present online, even when that person is trying to act deceptively; for example, people are relatively good at detecting when someone is a man even when they profess to be a woman online. ${ }^{38}$ Yet because mediated environments reveal different signals, the mechanisms of deception differ. ${ }^{39}$

\section{Writing Identity and Community into Being}

A MySpace profile can be seen as a form of digital body where individuals must write themselves into being. Through profiles, teens can express salient aspects of their identity for others to see and interpret. They construct these profiles for their friends and peers to view. (We will complicate the issue of audience in the next section.) While what they present may or may not resemble their offline identity, their primary audience consists of peers that they know primarily offline-people from school, church, work, sports teams, etc. Because of this direct link between offline and online identities, teens are inclined to present the side of themselves that they believe will be well received by these peers.

The desire to be cool on MySpace is part of the more general desire to be validated by one's peers. Even though teens theoretically have the ability to behave differently online, the social hierarchies that regulate "coolness" offline are also present online. For example, it is cool to have Friends on MySpace but if you have too many Friends, you are seen as a MySpace whore. These markers of cool are rooted in the social culture of MySpace. One of the ways that coolness is articulated is through bulletin posts meant to attack those who have status online and offline. One such post is a satirical Top 10 list of "How To Be Cool On MySpace," which includes material like "Your MySpace name MUST contain symbols and incorrect spelling" and "All your blogs have to be about how bad your day was." While this post is meant to dismiss these common practices, when these posts are spread around, they simultaneously reinforce these norms in the process of mocking them.

Part of what solidifies markers of cool has to do with the underlying Friend network. MySpace Friends are not just people that one knows, but public displays of connections. ${ }^{40}$ 


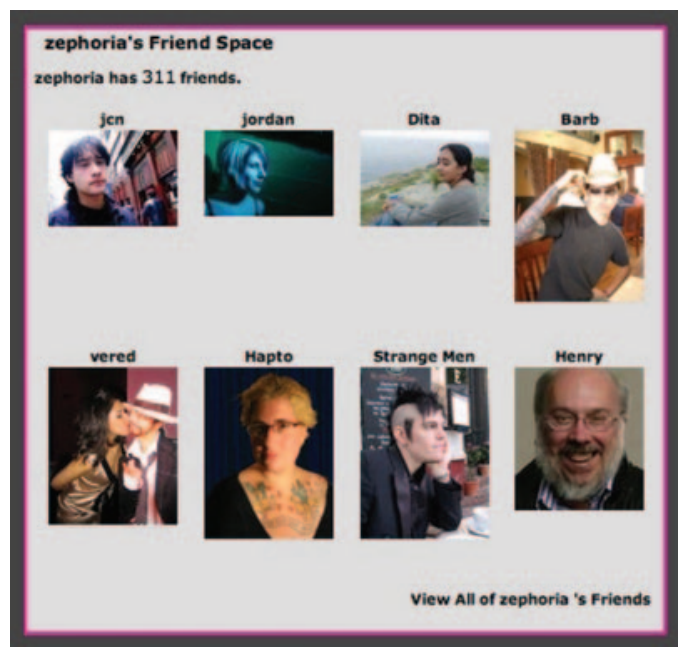

Figure 3

Example Top 8.

While teens will typically add friends and acquaintances as Friends, they will also add people because it would be socially awkward to say no to them, because they make the individual look cool, or simply because it would be interesting to read their bulletin posts. Because Friends are displayed on an individual's profile, they provide meaningful information about that person; in other words, "You are who you know." 41 For better or worse, people judge others based on their associations: group identities form around and are reinforced by the collective tastes and attitudes of those who identify with the group. Online, this cue is quite helpful in enabling people to find their bearings (see Figure 3).

The best indicator of an individual's close friends is their Top Friends (see Figure 3); these are displayed directly on an individual's profile, while the rest of their Friends require an additional click. Individuals can choose which Friends will be displayed. While the Top Friends feature allows members to quickly get to and show off the profiles of their closest friends, the public nature of this display tends to complicate relationships. In short, the Top Friends feature is considered pure social drama:

Myspace always seems to cause way too much drama and i am so dang sick of it. im sick of the pain and the hurt and tears and the jealousy and the heartache and the truth and the lies ... it just SUCKS!... im just so sick of the drama and i just cant take it anymore compared to all the love its supposed to make us feel. i get off just feeling worse. i have people complain to me that they are not my number one on my top 8. come on now. grow up. its freaking myspace." -Olivia, 17

The reason that the Top Friends feature wreaks social havoc on teens' lives is because there are social consequences in publicly announcing one's friends, best friends, and bestest friends. Feelings are hurt when individuals find that someone that they feel close with does not reciprocate.

As a kid, you used your birthday party guest list as leverage on the playground. 'If you let me play I'll invite you to my birthday party.' Then, as you grew up and got your own phone, it was all about someone being on your speed dial. Well today it's the MySpace Top 8. It's the new dangling carrot for 
gaining superficial acceptance. Taking someone off your Top 8 is your new passive aggressive power play when someone pisses you off. -Nadine, 16

Yet, for all of the social discomfort, these Friends help provide group structure, further indicating the meaningful identity markers of the individual. In choosing Friends, teens write their community into being, which is precisely why this feature is so loved and despised.

As discussed in the introduction to this volume, identity can be seen as a social process that is fluid and contingent on the situation. ${ }^{42}$ On MySpace, an individual's perceived audience frames the situation. While others might be present, the markers of cool are clearly dictated by an individual's friends and peers. What teens are doing here is conceptualizing an imagined audience. ${ }^{43}$ While this may seem peculiar, it is a practice that is commonplace for people like writers and actors who regularly interact with the public through mediating technologies. Without having cues about who will witness a given expression, an imagined audience provides a necessary way of envisioning who should be present. The size and diversity of this imagined community depends on the individual; some imagine acquiring fans while others imagine a community that is far more intimate. As Stern discusses earlier in this volume, youth's views on audience are quite nuanced. ${ }^{44}$ While some value the possibility of a wide audience, actually attracting such an audience can introduce complications. At the same time, wanting a large audience does not mean that a large audience will appear; online, everyone is famous to fifteen people. ${ }^{45}$

Regardless of desires, it is impossible to see the actual audience across all space and all time. At the same time, it is necessary to understand the scope of one's audience to properly present oneself. By imagining an audience, regardless of its accuracy, teens are able to navigate the social situation required in crafting a profile. Because of the intricate connection between offline and online social worlds, the audience that teens envision online is connected to their social world offline, or to their hopes about the possible alternatives online. Yet, their audience online may not be who they think it is.

\section{Privacy in Public: Creating MY Space}

My mom always uses the excuse about the internet being 'public' when she defends herself. It's not like I do anything to be ashamed of, but a girl needs her privacy. I do online journals so I can communicate with my friends. Not so my mother could catch up on the latest gossip of my life. - Bly LauritanoWerner, $17 .{ }^{46}$

For Lauritano-Werner, privacy is not about structural limitations to access; it is about being able to limit access through social conventions. This approach makes sense if you recognize that networked publics make it nearly impossible to have structurally enforced borders. However, this is not to say that teens also do not try to create structural barriers.

Teens often fabricate key identifying information like name, age, and location to protect themselves (see Figure 4). While parents' groups often encourage this deception to protect teens from strangers, ${ }^{47}$ many teens actually engage in this practice to protect themselves from the watchful eye of parents.

Fabricating data does indeed make search more difficult, but the networked nature of MySpace provides alternate paths to finding people. First, few teens actually lie about what school they attend, although some choose not to list a school at all. Second, and more problematically, teens are not going to refuse connections to offline friends even though that makes them more easily locatable. Parents simply need to find one of their child's friends; from there, it is easy to locate their own kid. While teens are trying to make parental 


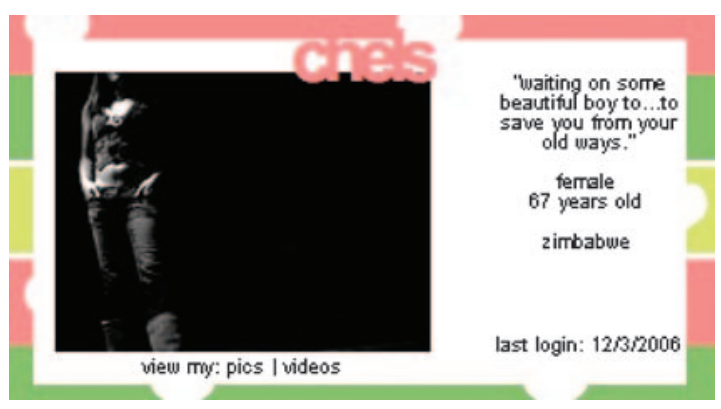

Figure 4

The formal data she provides MySpace says she is sixty-seven and from Zimbabwe; in her self-description, she indicates that she is actually fourteen and goes to high school in Texas.

access more difficult, their choice to obfuscate key identifying information also makes them invisible to their peers. This is not ideal because teens are going online in order to see and be seen by those who might be able to provide validation.

Another common structural tactic involves the privacy settings. By choosing to make their profile private, ${ }^{48}$ teens are able to select who can see their content. This prevents unwanted parents from lurking, but it also means that peers cannot engage with them without inviting them to be Friends. To handle this, teens are often promiscuous with who they are willing to add as Friends on the site. By connecting to anyone who seems interesting, they gain control over the structure. Yet, this presents different problems because massive Friending introduces a flood of content with no tools to manage it.

Another structural approach intended to confound parents is creating mirror networks. When Stacy's mom found her profile, she was outraged. She called the moms of two of Stacy's friends-Anne and Kimberly. All three parents demanded that their kids clean up their profiles and told them to tell their friends the same or else more parents would be called. Steamed by the prudish response of their parents, Stacy, Anne, and Kimberly reluctantly agreed to change their profiles. Then, they each made a second account with fake names and details. Here, they linked to each other's second profile and uploaded the offending material, inviting their friends to do the same. In doing so, they created a network that completely mirrored the network that their parents had seen. Their parents continued to check their G-rated profiles and the girls continued to lead undercover lives.

While deception and lockdown are two common structural solutions, teens often argue that MySpace should be recognized as my space, a space for teenagers to be teenagers. Adults typically view this attitude as preposterous because, as they see it, since the technology is public and teens are participating in a public way, they should have every right to view this content. This attitude often frustrates teenagers who argue that just because anyone can access the site does not mean that everyone should.

When teens argue for having my space in a networked public, they are trying to resolve the social problems that emerge because the constructions of public and private are different online and offline. In unmediated spaces, structural boundaries are assessed to determine who is in the audience and who is not. The decision to goof off during lunch is often made with the assumption that only peers bear witness. In mediated spaces, there are no structures to limit the audience; search collapses all virtual walls. 
Most people believe that security through obscurity will serve as a functional barrier online. For the most part, this is a reasonable assumption. Unless someone is of particular note or interest, why would anyone search for them? Unfortunately for teens, there are two groups who have a great deal of interest in them: those who hold power over them-parents, teachers, local government officials, etc.-and those who wish to prey on them-marketers and predators. Before News Corporation purchased MySpace, most adults had never heard of the site; afterwards, they flocked there either to track teenagers that they knew or to market goods (or promises) to any teen who would listen. This shift ruptured both the imagined community and the actual audience they had to face on a regular basis. With a much wider audience present, teens had to face a hard question: what is appropriate?

This problem is not unique to social network sites; it has been present in all forms of mediated publics. Consider Stokely Carmichael's experience with radio and television. ${ }^{49}$ As an activist in the 1960s, Carmichael regularly addressed segregated black and white audiences about the values and ideals of the burgeoning Black Power movement. Depending on the color of his audience, he used very different rhetorical styles. As his popularity grew, he started attracting media attention and was invited to speak on TV and radio. This opportunity was also a curse because both black and white listeners would hear his speech. As there was no way to reconcile the two different rhetorical styles he typically used, he had to choose. By maintaining his black roots in front of white listeners, Carmichael permanently alienated white society from the messages of Black Power. Faced with two disjointed contexts simultaneously, there was no way that Carmichael could successfully convey his message to both audiences.

Teenagers face the same dilemma on MySpace. How can they be simultaneously cool to their peers and acceptable to their parents? For the most part, it is not possible. While most adults wish that kids would value what they value, this is rarely true. It is easy to lambaste teens for accepting the cultural norms of the "in" crowd, but social categories ${ }^{50}$ and status negotiation ${ }^{51}$ are core elements in teen life; this is part of how they learn to work through the cultural practices and legal rules that govern society. The behaviors that are typically rewarded with status in school are often resistant to adult values. On MySpace, teens are directly faced with peer pressure and the need to conform to what is seen to be cool. Worse, they are faced with it in the most public setting possible-one that is potentially visible to all peers and all adults. The stakes are greater on both sides, but the choice is still there: cool or lame?

Unfortunately, the magnified public exposure increases the stakes. Consider a call that I received from an admissions officer at a prestigious college. The admissions committee had planned to admit a young black man from a very poor urban community until they found his MySpace. They were horrified to find that his profile was full of hip-hop imagery, urban ghetto slang, and hints of gang participation. This completely contradicted the essay they had received from him about the problems with gangs in his community, and they were at a loss. Did he lie in his application? Although confidentiality prevented me from examining his case directly, I offered the admissions officer an alternative explanation. Perhaps he needed to acquiesce to the norms of the gangs while living in his neighborhood, in order to survive and make it through high school to apply to college?

Situations like this highlight how context is constructed and maintained through participation, not simply observation. When outsiders search for and locate participants, they are ill prepared to understand the context; instead, they project the context in which they relate to the individual offline onto the individual in this new online space. For teens, this 
has resulted in expulsions, suspensions, probations, and being grounded. ${ }^{52}$ In Pennsylvania, a student's parody of his principal was not read as such when the principal found this profile on MySpace; the student was removed from school and lawsuits are still pending. ${ }^{53}$ Of course, not every misreading results in the punishment of youth. Consider the story of Allen and his daughter Sabrina. Because Sabrina thinks her dad is cool, she invited him to join her on MySpace. Upon logging in, Allen was startled to see that her profile included a quiz entitled "What kind of drug are you?," to which she had responded "cocaine." Confused and horrified, Allen approached his daughter for an explanation. She laughed and explained, "it's just one of those quizzes that tells you about your personality... but you can kinda get it to say what you want." She explained that she did not want to be represented by marijuana because the kids who smoked pot were lame. She also thought that acid and mushrooms were stupid because she was not a hippie. She figured that cocaine made sense because she heard that people did work on it and, "besides Dad, your generation did a lot of coke and you came out OK." This was not the explanation that Allen expected.

Teens are not necessarily well prepared to navigate complex social worlds with invisible audiences, but neither are adults. While Allen was able to talk with his daughter about other possible interpretations of her choice in presentation, he recognized that her profile was not meant for such audiences. How could he teach her how to engage in identity presentation while navigating multiple audiences? While MySpace is public, it is unlike other publics that adults commonly face. This presents a generational divide that is further complicated by adults' misreadings of youth participation in new media. ${ }^{54}$

But Why There? The power that adults hold over youth explains more than just complications in identity performance; it is the root of why teenagers are on MySpace in the first place. In the United States, the lives of youth-and particularly high school teenagers-are highly structured. Compulsory high school requires many students to be in class from morning to midafternoon; and many are also required to participate in after-school activities, team sports, and work into the evening. It is difficult to measure whether today's high school teens have more or less free time than previous generations, but the increased prevalence of single working parent and dual-working parent households implies that there are either more latchkey kids or more after-school programs watching these kids. ${ }^{55}$ Given the overwhelming culture of fear and the cultural disdain for latchkey practices, it is likely that teens are spending more time in programs than on their own. Meanwhile, at home in the evenings, many are expected to do homework or spend time with the family. While the home has been considered a private sphere where individuals can regulate their own behavior, this is an adult-centric narrative. For many teens, home is a highly regulated space with rules and norms that are strictly controlled by adults.

Regardless of whether teens in the United States have the time to engage in public life, there are huge structural and social barriers to their doing so. First, there is an issue of mobility. While public transit exists in some urban regions, most of the United States lacks adequate transportation options for those who are unable to drive; given the suburbanization of the United States, teens are more likely to live in a region without public transit than one with public transit. There is a minimum age for drivers in every state, although it varies from sixteen to eighteen. A license is only one part of the problem; having access to a car is an entirely separate barrier to mobility. This means that, for many teens, even if they want to go somewhere they are often unable to do so. 
American society has a very peculiar relationship to teenagers-and children in general. They are simultaneously idealized and demonized; adults fear them but they also seek to protect them. ${ }^{56}$ On one hand, there has been a rapid rise in curfew legislation to curb teen violence $^{57}$ and loitering laws are used to bar teens from hanging out on street corners, in parking lots, or other outdoor meeting places for fear of the trouble they might cause. On the other hand, parents are restricting their youth from hanging out in public spaces for fear of predators, drug dealers, and gangs. Likewise, while adults spend countless hours socializing over alcohol, minors are not only restricted from drinking but also from socializing in many venues where alcohol is served.

Moral entrepreneurs have learned that "invoking fears about children provides a powerful means of commanding public attention and support." ${ }^{58}$ This ongoing culture of fear typically overstates the actual dangers and obfuscates real risks in the process. ${ }^{59}$ Yet, the end result of this is that youth have very little access to public spaces. The spaces they can hang out in are heavily controlled and/or under surveillance:

My [guardian] is really strict so if I get to go anywhere, it's a big miracle. So I talk to people on MySpace... I know she means well, I know she doesn't want me to mess up. But sometimes you need to mess up to figure out that you're doing it wrong. You need mistakes to know where you're going. You need to figure things out for yourself. - Traviesa, 15

Many adults believe that these restrictions are necessary to prevent problematic behaviors or to protect children from the risks of society. Whether or not that view is valid, restrictions on access to public life make it difficult for young people to be socialized into society at large. While social interaction can and does take place in private environments, the challenges of doing so in public life are part of what help youth grow. Making mistakes and testing limits are fundamental parts of this. Yet, there is a pervading attitude that teens must be protected from their mistakes.

At the beginning of this chapter, I explained that I would use the term teenagers to refer to youth of high school age living at home. In doing so, I glossed over how problematic any definition of youth or teenager is. ${ }^{60}$ Yet, it is precisely the construction of teenager/youth in opposition to adult that creates the power dynamic upon which most of the challenges stated earlier hinge. The term teenager did not exist a century ago. It was most likely coined in the 1920s or 1930s, and it first appeared in print as a marketing term in $1941 .^{61}$ The notion of a young adult did exist and it primarily referenced young people who were entering the workforce. By about fourteen, most young people began laboring outside the home; they continued to live with their parents and their income helped the family pay its costs. The workforce was a critical site of socialization into adulthood for young people; very few went to high school or college. This changed in the United States during the Great Depression. With too few jobs and too many adults needing employment, the labor movement joined social reformers who had been urging the government to require high school attendance for young people. While social reformers believed that young people were not mature enough to be entering the workforce, the labor movement was more interested in keeping young adults out of the work force (and off the streets). Together, they were able to convince Congress to pass compulsory education and child labor laws.

While the appropriateness of this move can be debated, its effect was clear: young people were neatly segregated from adults in all aspects of their lives. Through funding structures, schools were encouraged to consolidate into large institutions that could support at least 100 students per year and provide activities and sports that kept youth from mixing with 
adult laborers in leisure as well as work. The school reform that took place during this era created the iconic American high school imagery that Hollywood popularized around the world during the second half of the twentieth century. Idealists viewed high school as a place where youth could mature both intellectually and socially, but age segregation meant that young people were being socialized into a society that did not include adults. While peer socialization is obviously valuable and important, it is fundamentally different from being socialized into adult society by adults themselves; generations emerge and norms change rapidly per generation. By segregating people by age, a true dichotomy between adult and teen emerged.

The development of an age-segregated group also created a target demographic for marketers. Following World War II, organizations and corporations began explicitly targeting teens directly, appealing to the tastes and values generated in teen culture. Spaces like dance halls, roller rinks, bowling alleys, and activity centers began offering times for teens to socialize with other teens. (These spaces, once vibrant in the United States, are virtually extinct now.) Businesses welcomed middle- and upper-class teens with open arms because of their perceived consumer power. Products began to be designed explicitly for teens. This consumer process similarly reinforced separate youth and adult publics.

By late-twentieth century, shopping malls became the primary "public" space for youth socialization. ${ }^{62}$ While shopping malls once welcomed teens, now they are primarily seen as a nuisance. Shopkeepers are wary of teens because of shoplifting and they are often ejected for loitering. While the public spaces built around consumerism have become increasingly hostile to teenagers, they still rabidly market to them. In other words, teens are still a marketable demographic for products, even if there is little interest in providing services for them.

This dynamic, while overly simplified for brevity's sake, does not properly convey the differences across different social groups within the American society. It is primarily the story of white, middle class, suburban teens. Poor teens and people of color were never given access to these types of spaces in the first place. That said, commercialism has moved on to coopt the spaces that these groups do traverse. The corporatization and glorification/demonization of hip-hop and "the 'hood" is one example of this. ${ }^{63}$ As we move toward a more global market, multinational corporations are expanding on their desire to target niche groups of teens, simultaneously supporting the attitude that teens are both angels and demons.

Collectively, four critical forces ${ }^{64}$ - society, market, law, and architecture-have constructed an age-segregated teen culture that is deeply consumerist but lacks meaningful agency. The contradictions run deep-we sell sex to teens but prohibit them from having it; we tell teens to grow up but restrict them from the vices and freedoms of adult society. ${ }^{65}$ Teenagers have navigated and challenged this hypocrisy over decades. Changes in society, market, and law have shifted the perception and treatment of youth. What emerged with the Internet was a radical shift in architecture; it decentralized publics.

While the jury is still out on whether or not the Internet is democratizing, online access provides a whole new social realm for youth. Earlier mediated communication deviceslandline, pager, mobile-allowed friends to connect with friends even when located in adult-regulated physical spaces. What is unique about the Internet is that it allows teens to participate in unregulated publics while located in adult-regulated physical spaces such as homes and schools. Of course, this is precisely what makes it controversial. Parents are seeking to regulate teens' behavior in this new space; and this, in turn, is motivating teens to hide. 
A few of my friends won't even dare to tell their parents about their MySpace cause they know they'll be grounded forever. I know two kids who got banned from it but they secretly got back on. —Ella, 15

Yet, putting aside the question of risk, what teens are doing with this networked public is akin to what they have done in every other type of public they have access to: they hang out, jockey for social status, work through how to present themselves, and take risks that will help them to assess the boundaries of the social world. They do so because they seek access to adult society. Their participation is deeply rooted in their desire to engage publicly, for many of the reasons we have discussed earlier. By prohibiting teens from engaging in networked publics, we create a participation divide, ${ }^{66}$ both between adults and teens and between teens who have access and those who do not.

\section{Conclusion}

Publics play a crucial role in the development of individuals for, as Nancy Fraser explains, "they are arenas for the formation and enactment of social identities." ${ }^{67}$ By interacting with unfamiliar others, teenagers are socialized into society. Without publics, there is no coherent society. Publics are where norms are set and reinforced, where common ground is formed. Learning society's rules requires trial and error, validation and admonishment; it is knowledge that teenagers learn through action, not theory. Society's norms and rules only provide the collectively imagined boundaries. Teenagers are also tasked with deciding how they want to fit into the structures that society provides. Their social identity is partially defined by themselves and partially defined by others. Learning through impression management is key to developing a social identity. Teenagers must determine where they want to be situated within the social world they see, and then attempt to garner the reactions to their performances that match their vision. This is a lifelong process, but one that must be supported at every step.

In today's society, there is a push toward privacy. It is assumed that people are public individuals who deserve the right to privacy rather than the other way around. With an elevated and idealized view of privacy, we often forget the reasons that enslaved peoples desperately wished for access to public life. By allowing us to have a collective experience with people who are both like and unlike us, public life validates the reality that we are experiencing. We are doing our youth a disservice if we believe that we can protect them from the world by limiting their access to public life. They must enter that arena, make mistakes, and learn from them. Our role as adults is not to be their policemen, but to be their guides.

Of course, as Hannah Arendt wrote long before the Internet, "everything that appears in public can be seen and heard by everybody and has the widest possible publicity." 68 What has changed with the emergence of new tools for mediating sociality is the scale and persistence of possible publicity. For most people in history, public life was not documented and distributed for the judgment of others who were not present. Only aristocrats and celebrities faced that type of public because structural and social forces strongly limited the "widest possible publicity." Not everything could be documented and spreading information was challenging. Only the lives of the rich and famous were deemed important enough to share.

The Internet has irrevocably changed this. Teens today face a public life with the possibility of unimaginably wide publicity. The fundamental properties of networked 
publics—persistence, searchability, replicability, and invisible audiences—are unfamiliar to the adults that are guiding them through social life. It is not accidental that teens live in a culture infatuated with celebrity ${ }^{69}$ - the "reality" presented by reality TV and the highly publicized dramas (such as that between socialites Paris Hilton and Nicole Richie) portray a magnified (and idealized) version of the networked publics that teens are experiencing, complete with surveillance and misinterpretation. The experiences that teens are facing in the publics that they encounter appear more similar to the celebrity idea of public life than to the ones their parents face.

It is not as though celebrities or teenagers wish for every conversation to be publicly available to everyone across all time and space, but mediated publics take the simplest public expressions and make them hyperpublic. Few adults could imagine every conversation they have sitting in the park or drinking tea in a café being available for such hyperpublic consumption, yet this is what technology enables; there is an ethos that if it is possible to access a public expression, one should have the right to do so.

While we can talk about changes that are taking place, the long-term implications of being socialized into a culture rooted in networked publics are unknown. Perhaps today's youth will be far better equipped to handle gossip as adults. Perhaps not. What we do know is that today's teens live in a society whose public life is changing rapidly. Teens need access to these publics - both mediated and unmediated - to mature, but their access is regularly restricted. Yet, this technology and networked publics are not going away. As a society, we need to figure out how to educate teens to navigate social structures that are quite unfamiliar to us because they will be faced with these publics as adults, even if we try to limit their access now. Social network sites have complicated our lives because they have made this rapid shift in public life very visible. Perhaps instead of trying to stop them or regulate usage, we should learn from what teens are experiencing. They are learning to navigate networked publics; it is in our better interest to figure out how to help them.

\section{Notes}

1. Quote posted by her mother Kathy Sierra: http://headrush.typepad.com/creating_passionate_users/ 2006/03/ultrafast_relea.html (accessed January 9, 2007).

2. Part of a conversation from December 2004 that motivated Parry Aftab (Executive Director of Wired Safety) to help teens use social network sites safely; story shared by one of her "Teen Angels" (http://www.teenangels.com).

3. Clifford Geertz, The Interpretation of Cultures (New York: Basic Books, 1973).

4. Thomas Hine, The Rise and Fall of the American Teenager (New York: Bard, 1999).

5. Amanda Lenhart, Mary Madden, and Paul Hitlin, Teens and Parents Survey, PEW Internet and American Life Project (October-November 2004).

6. Amanda Lenhart, Social Networking Websites and Teens: An Overview, PEW Internet and American Life Project (7 January 2007).

7. In conducting phone interviews, PEW first speaks with the parent and then the child. It is quite likely that the child's answers are influenced by the presence of their parents. With social network sites, the overwhelming disapproval of most parents suggests that teens are more likely to say "no" if affected by the presence of their parents. Furthermore, this does not account for the number of teens who have had profiles made for them and my qualitative experience has shown that teens who formerly had a profile 
will often say "no" when asked if they ever created a profile. That said, PEW is unlikely to be off by more than 10 percent.

8. In a private message, Mary Gray (Indiana University) shared that her research in Kentucky shows that rural teens have no access to MySpace because they access the Internet at schools and libraries, where MySpace is banned.

9. There is nothing to confirm that the person being represented is the person behind the profile. Teens are most notorious for maliciously creating fraudulent profiles to bully the represented, but it is equally common for teens to create profiles for their friends. Because one's friends are made visible on one's profile, teens complain that their profile is ruined if their best friend does not have a profile that can be listed as a Friend on the site.

10. Amanda Lenhart, Social Networking Websites and Teens, 2007.

11. danah boyd (in press), None of This Is Real, in Structures of Digital Participation, ed. Joe Karaganis. Social Science Research Council, in press.

12. danah boyd, Friendster and Publicly Articulated Social Networks, Proceedings of Conference on Human Factors and Computing Systems (CHI 2004) (Vienna: ACM, 2004).

13. Sarah Thornton, Club Cultures: Music, Media, and Subcultural Capital (Middletown, CT: Wesleyan University Press, 1996).

14. See Rebekah Willett in this volume.

15. There is no published documentation of the caste segmentation in Orkut although there is a discussion about the issue on the "I, Me, and Media" blog (http://differentstrokes.blogspot.com/2006/09/castecommunities-on-orkut.html), and I was able to confirm this dynamic with Orkut's product manager. (Accessed January 10, 2007).

16. Defining a category through articulated boundaries is problematic (see George Lakoff, Women, Fire, and Dangerous Things [Chicago: University of Chicago Press, 1987]). My effort to do so is to distinguish what is unique to this new style of site from previous types of social software. Although this definition brings some clarity, newer social software is beginning to implement these features into sites that are predominantly about video sharing (YouTube), photo sharing (Flickr), music tastes (Last.FM), etc. The social network sites that I discuss here are first and foremost about the friends' network, while these newer sites are primarily about media sharing or discovery.

17. For legibility, when I am referring to the Friends feature on MySpace, I capitalize the term. When I am referring to people that individuals would normally talk about as their friends, I do not.

18. For a more detailed analysis on the Friending process, see danah boyd, Friends, Friendsters, and MySpace Top 8: Writing Community Into Being on Social Network Sites, First Monday 11, no. 12 (2006). http://www.firstmonday.org/issues/issue11_12/boyd/ (accessed January 10, 2007).

19. danah boyd and Jeffrey Heer, Profiles as Conversation: Networked Identity Performance on Friendster, in Proceedings of the Hawai'i International Conference on System Sciences (HICSS-39), Persistent Conversation Track (Kauai, HI: IEEE Computer Society, January 4-7, 2006).

20. Most social network sites support private messaging so that people can contact other members directly. Some sites support blogging and posting of videos. MySpace and Friendster have a bulletin feature where participants can post messages that all of their Friends can read. Other features that appear on social network sites include instant messaging, teacher ratings, message boards, groups, and classified ads. Exactly how these features are implemented differs by site.

21. For a primer on some of the key debates concerning "public" and "public sphere," see Craig Calhoun, Habermas and the Public Sphere (Cambridge, MA: MIT Press, 1992). 
22. Sonia Livingstone, "Introduction" and "On the Relation Between Audiences and Publics," in $A u$ diences and Publics: When Cultural Engagement Matters for the Public Sphere, ed. Sonia Livingstone, 9-14 (Bristol, UK: Intellect, 2005).

23. Op. cit.

24. Michael Warner, The Mass Public and the Mass Subject, in Habermas and the Public Sphere, ed. Craig Calhoun (Cambridge, MA: MIT Press, 1992), 377-401.

25. Mizuko Ito (in press), Introduction, in Networked Publics (Cambridge, MA: MIT Press).

26. Nicholas Negroponte, Being Digital (New York: Vintage, 1996).

27. The power of technology to support always-on intimate communities is articulated in Mizuko Ito, Daisuke Okabe, and Misa Matsuda, Personal, Portable, Pedestrian: Mobile Phones in Japanese Life (Cambridge, MA: MIT Press, 2005).

28. While MySpace recognized this hole within hours, they did not close the loophole nor did they begin supporting the practice. They allowed it to exist as an underground copy/paste culture. They have banned the specific code that puts the site and participants at risk. For example, they block Javascript to make it harder for scammers to prey on members.

29. While the original copy/paste sites were created by teenagers, it is not clear who runs the thousands of code sites currently operating. Most make money off of advertising, so it is likely to be a business venture. Scammers looking to exploit participants' willingness to copy/paste anything probably run some as well.

30. "Pimp out" is a slang term that basically means "make cool" (by teen standards). Pimped out profiles usually involve heavy modifications to the templates and numerous multimedia components. What looks pimped out to a teen is typically viewed as horrifyingly chaotic to adults. Technologists complain that the design resembles that of early homepages with blink tags and random colors. The best way that I've found to describe what these profiles look like is a highly decorated teenage bedroom wall or locker.

31. Dan Perkel, Copy and Paste Literacy: Literacy Practices in the Production of a MySpace ProfileAn Overview, in Proceedings of Informal Learning and Digital Media: Constructions, Contexts, Consequences (Denmark, September 21-23, 2006).

32. Fred Davis, Fashion, Culture and Identity (Chicago: University of Chicago Press, 1992).

33. Erving Goffman, The Presentation of Self in Everyday Life (Edinburgh: University of Edinburgh, 1956).

34. Erving Goffman, Behavior in Public Places (New York: The Free Press, 1963).

35. Jean Briggs, Inuit Morality Play: The Emotional Education of a Three-Year-Old (New Haven, CT: Yale University Press, 1999).

36. Jenny Sundén, Material Virtualities (New York: Peter Lang Publishing, 2003).

37. See David Buckingham's introduction to this volume for a greater discussion of this.

38. Joshua Berman and Amy Bruckman, The Turing Game: Exploring Identity in an Online Environment, Convergence 7, no. 3 (2001): 83-102.

39. Judith Donath, Identity and Deception in the Virtual Community, Communities in Cyberspace, eds. Marc Smith and Peter Kollock (London: Routledge, 1999).

40. Judith Donath and danah boyd, Public Displays of Connection, BT Technology Journal 22, no. 4 (October 2004): 71-82. 
41. Like "guilt by association," this phrase is logically fallible, but people still judge others based on those around them (see Irving David Shapiro, "Fallacies of Logic: Argumentation Cons," ETC.: A Review of General Semantics 33, no. 3 [Fall 1996]: 251-265).

42. See David Buckingham's Introduction to this volume, 2007.

43. Benedict Anderson coined the term "imagined community" to discuss nationality. In talking about "imagined audiences," I am drawing on his broader point about how communities can be socially constructed and imagined by those who see themselves as members (Benedict Anderson, Imagined Communities [New York: Verso, 1991]).

44. To follow this thread, see Susannah Stern's chapter in this volume.

45. This riff on Andy Warhol's infamous comment has circulated the web; I am not sure where to properly locate its origin.

46. Bly Lauritano-Werner, 2006. Reading My LiveJournal. Youth Public Radio. http://youthradio.org/ society/npr060628_onlinejournal.shtml (accessed June 28, 2007).

47. Kevin Farnham and Dale Farnham, MySpace Safety: 51 Tips for Teens and Parents (Pomfret, CT: How-To Primers, 2006).

48. Private profiles in MySpace are visible to Friends only. When strangers visit their page, they are shown the primary photo, name, location, age, and a saying. They must become Friends with that person to see the rest of the content.

49. Joshua Meyrowitz, No Sense of Place (New York: Oxford, 1985).

50. Penelope Eckert, Jocks \& Burnouts: Social Categories and Identity in the High School (New York: Teacher College Press, 1989).

51. Murray Milner Jr., Freaks, Geeks, and Cool Kids: American Teenagers, Schools, and the Culture of Consumption (New York: Routledge, 2004).

52. Alex Koppelman, 2006. MySpace or OurSpace? Salon. http://www.salon.com/mwt/feature/2006/06/ 08/my_space/ (accessed June 8, 2007).

53. Kevin Poulson, 2006. Scenes from the MySpace Backlash, Wired News, February 27, 2006. http://www.wired.com/news/politics/1,70254-0.html (accessed January 10, 2007).

54. To follow this thread, see Susan Herring's chapter in this volume.

55. Julia Overturf Johnson, Robert Kominski, Kristin Smith, and Paul Tillman, Changes in the Lives of U.S. Children 1990-2000. Working Paper No 78, United States Census Bureau (November 2005).

56. Joe Austin and Michael Nevin Willard, Introduction: Angels of History, Demons of Culture, Generations of Youth: Youth Cultures and History in Twentieth-Century America, eds. Joe Austin and Michael Nevin Willard (New York: New York University Press, 1998), 1-20.

57. William Ruefle and Kenneth Reynolds, Curfew and Delinquency in Major American Cities, Crime and Delinquency 41 (1995): 347-363.

58. David Buckingham, After the Death of Childhood (Oxford: Polity, 2000), 11.

59. Barry Glassner, The Culture of Fear: Why Americans Are Afraid of the Wrong Things (New York: Basic Books, 2000).

60. See David Buckingham's introduction in this volume.

61. The history in this paragraph is well documented and cited in Thomas Hine, The Rise and Fall of the American Teenager, 1999. 
62. Margaret Crawford, The World in a Shopping Mall, Variations on a Theme Park: The New American City and the End of Public Space, ed. Michael Sorkin (New York: Hill and Wang, 1992), 3-30.

63. Murray Forman, The 'Hood Comes First: Race, Space, and Place in Rap and Hip-Hop (Middletown, CT: Wesleyan University Press, 2002).

64. Lawrence Lessig, Code and Other Laws of Cyberspace (New York: Basic Books, 1999).

65. The contradictions and challenges of youth as a social construct are well articulated in David Buckingham, After the Death of Childhood, 2000.

66. Henry Jenkins, Confronting the Challenges of Participatory Culture: Media Education for the 21st Century, White Paper for MacArthur Foundation, 2006.

67. Nancy Fraser, Rethinking the Public Sphere: A Contribution to the Critique of Actually Existing Democracy, Habermas and the Public Sphere, ed. Craig Calhoun (Cambridge, MA: MIT Press, 1992), 125.

68. Hannah Arendt, The Human Condition (Chicago: University of Chicago Press, 1958), 50.

69. Jake Halpern, Fame Junkies: The Hidden Truths Behind America's Favorite Addiction (Boston: Houghton Mifflin, 2007). 